\section{A modified toxigenicity test for Corynebacterium diphtheriae}

\author{
S. HAYDEN-SMITH AND L. SCHRIRE From the \\ South African Institute for Medical Research, \\ Johannesburg
}

The gel-precipitation method for the determination of the toxigenicity of Corynebacterium diphtheriae, as described by Elek (1948), has been in use in this laboratory as a routine procedure since 1949. In view of the difficulty often experienced in reading weakly positive results, the technique was modified as described below.

\section{METHOD}

Prepare the basic medium as described by Elek, and distribute $10 \mathrm{ml}$. amounts into sterile $9 \mathrm{~cm}$. petri dishes. These should be stored at $4^{\circ} \mathrm{C}$. until required. Before carrying out a test, allow the surface of the medium to dry in an incubator for 20 to 30 minutes.

Saturate a sterile $6 \mathrm{~mm}$. disc of Ford's 428 mill filter paper with diphtheria antitoxin containing approximately 2,000 units per $\mathrm{ml}$. Place the disc on the medium and inoculate the culture at a distance of $6 \mathrm{~mm}$. from the edge of the disc, over an area roughly the size of the disc. For this purpose it is convenient to place the petri dish on a white card marked with two concentric circles, $6 \mathrm{~mm}$. and $18 \mathrm{~mm}$. in diameter respectively. The disc can then be centred over the smaller circle, and the cultures inoculated in such a way that the nearest point of the inoculum is $6 \mathrm{~mm}$. from the disc.

Four cultures may be tested around each disc. As four discs can be accommodated on each plate, a total of 15 tests and a positive control (Park-Williams 8) can be carried out on one petri dish.

Incubate at $37^{\circ} \mathrm{C}$. and examine after 24 hours. A positive result is indicated by the appearance of fine white lines of precipitation tangentially between the disc and the test cultures. It is possible to read the plates after an incubation period of six hours, when a hand lens should Received for publication 4 May 1961. be used. After 24 hours of incubation, the white lines can easily be seen with the naked eye.

\section{RESULTS}

One hundred routinely isolated strains of $C$. diphtheriae were tested in parallel for toxigenicity by using, 1 , the standard Elek test, 2, the modified test, and 3, the intradermal method in the guinea-pig. The results are shown in Table I.

\begin{tabular}{lccc}
$\begin{array}{l}\text { No. of Cultures } \\
\text { Tested }\end{array}$ & $\begin{array}{l}\text { TABLE I } \\
\text { Positive } \\
\text { (standard) }\end{array}$ & $\begin{array}{l}\text { Positive } \\
\text { (modified) }\end{array}$ & $\begin{array}{l}\text { Positive } \\
\text { (guinea-pig }\end{array}$ \\
\hline 100 & 90 & 95 & 95
\end{tabular}

A further 200 cultures were tested by the modified $\vec{r}$ method together with guinea-pig inoculation tests. The $\vec{e}$ results show almost complete correspondence betweeno the two methods (Table II).

\section{TABLE II}

\begin{tabular}{ccc}
$\begin{array}{l}\text { No. of Cultures } \\
\text { Tested }\end{array}$ & $\begin{array}{c}\text { Positive } \\
\text { (modified) }\end{array}$ & $\begin{array}{l}\text { Positive } \\
\text { (guinea-pig }\end{array}$ \\
\hline 200 & 200 & 199 \\
& CONCLUSION
\end{tabular}

The modified Elek gel-precipitation test has the followingo advantages over the standard method:-

1 The plates can be prepared in batches and stored until required.

2 There is greater economy in the use of antitoxin as approximately $0.02 \mathrm{ml}$. is sufficient for four tests.

3 The time required for a positive result to manifesto itself is considerably reduced.

4 The clearly defined precipitation lines simplify the reading of the results.

We wish to thank the Director of the South African? Institute for Medical Research for kindly granting us the facilities for carrying out this investigation.

REFERENCE

Elek, S. D. (1948). Brit. med. J., 1, 493. 